
Not for reproduction, distribution or commercial use.

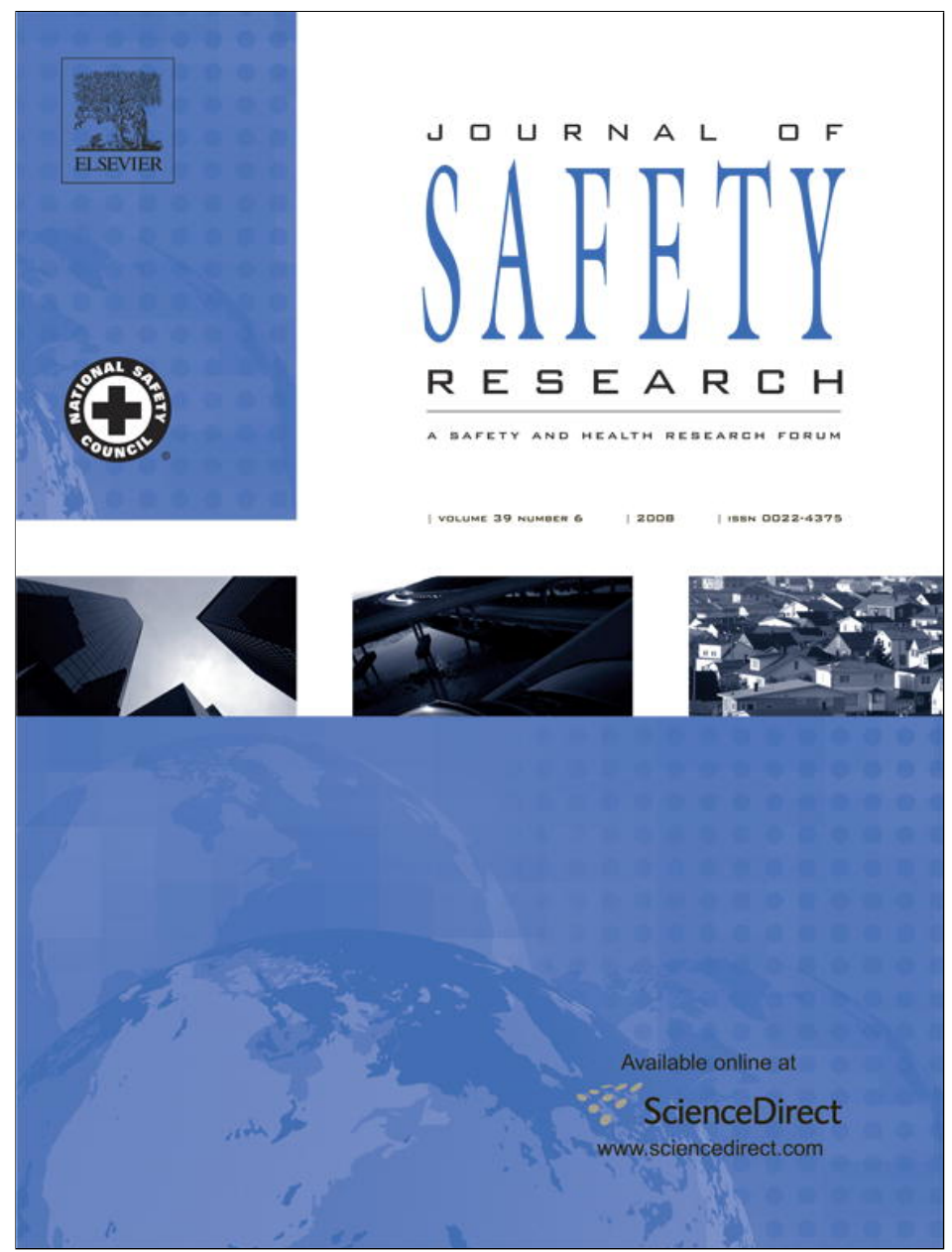

This article appeared in a journal published by Elsevier. The attached copy is furnished to the author for internal non-commercial research and education use, including for instruction at the authors institution and sharing with colleagues.

Other uses, including reproduction and distribution, or selling or licensing copies, or posting to personal, institutional or third party websites are prohibited.

In most cases authors are permitted to post their version of the article (e.g. in Word or Tex form) to their personal website or institutional repository. Authors requiring further information regarding Elsevier's archiving and manuscript policies are encouraged to visit:

http://www.elsevier.com/copyright 


\title{
Epidemiology of subway-related fatalities in New York City, 1990-2003
}

\author{
Robyn R.M. Gershon a,*, Julie M. Pearson a , Vijay Nandi ${ }^{\text {b }}$, David Vlahov ${ }^{\text {b }}$, Angela Bucciarelli-Prann ${ }^{\text {c }}$, \\ Melissa Tracy ${ }^{\mathrm{d}}$, Kenneth Tardiff ${ }^{\mathrm{e}}$, Sandro Galea ${ }^{\mathrm{d}}$ \\ ${ }^{a}$ Mailman School of Public Health, Columbia University, New York, NY \\ ${ }^{\mathrm{b}}$ New York Academy of Medicine, New York, NY \\ c Hackensack University Medical Center, Hackensack, NJ \\ d University of Michigan School of Public Health, Ann Arbor, MI \\ e Weill Medical College of Cornell University, New York, NY
}

\section{A R T I C L E I N F O}

Available online 14 November 2008

\section{Keywords:}

Subway

Fatalities

Epidemiology

Suicides

Accidents

\begin{abstract}
A B S T R A C T
Problem: Subway transit is a relatively safe mode of transportation, yet compared to all other forms of mass transit in the United States (U.S.), subways have the highest fatality rate. The aim of this paper is to characterize subway-related fatalities in order to identify opportunities for risk reduction. Method: Medical examiner records for all New York City (NYC) subway-related deaths (1990-2003) were reviewed. Data were abstracted on decedents' demographics and autopsy findings, including laboratory findings. Results: There were 668 subway-related fatalities, of these, 10 (1.5\%) were homicides, 343 (51.3\%) were determined to be suicides, and 315 (47.2\%) were accidental. Although decedent characteristics varied between fatality categories, they were not particularly informative with regard to prevention. Conclusion: Prevention strategies that focus on structural controls are likely to be most efficacious in improving the overall safety of the NYC subway systems. Impact on industry: These findings suggest that structural rather than individuallevel interventions would be most successful in preventing subway fatalities.
\end{abstract}

(C) 2008 National Safety Council and Elsevier Ltd. All rights reserved.

\section{Problem}

Mass transit, which includes all multiple occupancy vehicles (e.g., buses, heavy and light rails, cable cars, and tramways), is a critical infrastructure element in urban settings, providing affordable, convenient, and rapid transportation to millions of urban dwellers. To keep pace with the explosive growth of cities (by 2030, more than two thirds of the world's population, nearly 5 billion people, will live in cities; United Nations Population Fund, 2007), mass transit systems are rapidly being developed. In particular, the growth of subway systems, which have the largest passenger ridership, is especially striking. There are 135 subway systems worldwide, a 70\% increase over the last five years (Nelson, Dawkins, \& Sanchez, 2007). Six of the systems report over 1 billion passenger-rides each year, including the New York City (NYC) transit system (Jane's Urban Transport Systems, 2002-2003 ed.; The Light Rail Transit Association, 2006). NYC transit, the largest subway system in the United States, has nearly 5 million passengers (roughly 4.7 million riders) each weekday (Metropolitan Transportation Authority).

\footnotetext{
* Corresponding author. Columbia University, Mailman School of Public Health, 722 West 168th Street, New York, NY 10032. Tel.: +1 212305 1186; fax: +1 2123058284. E-mail address: rg405@columbia.edu (R.R.M. Gershon).
}

The navigation of this enormous volume of people through heavily congested subway pathways with narrow platforms, stairs, escalators, elevators, steep ramps, and transfer stations would appear to provide numerous opportunities for adverse incidents to occur. Yet, the number of subway-related injuries in the United States is considered quite low, with roughly 10,000 accidents per year (American Public Transportation Association, 2001). Most of these injuries appear to be related to slips, trips, and falls experienced by passengers (Mass Transit Association \& New York City Transit), although injuries related to derailments do occur.

Subway-related fatality rates in the United States are also comparatively low, with an average of 20-70 passenger deaths each year (American Public Transportation Association, 2005a). Compared to the fatality rate associated with automobile travel, subway-related fatalities are much lower; 0.77 vs. 0.01 per 100 million passenger-miles, respectively (American Public Transportation Association, 2005a,b, 2006). However, compared to all other forms of mass transit, including intercity and commuter railroads, intercity buses and transit buses, subways have higher (all causes) fatality rates (American Public Transportation Association, 2005a,b, 2006). This may be related, in part, to the number of subway-related suicides, a well documented problem associated with both subways and railroads throughout the world (Baumert, Erazo, \& Ladwig, 2006; Clarke, 1994; Gaylord \& Lester, 1994; Ladwig \& Baumert, 2004; Mishara, 2007; O'Donnell, Arthur, \& 
Farmer, 1994; O'Donnell \& Farmer, 1994; Rådbo, Svedung, \& Andersson, 2005; Ratnayake, Links, \& Eynan, 2007).

An ongoing public safety challenge has been to determine optimal prevention strategies to reduce subway-related fatalities, which are classified into two broad categories: intentional (i.e., violent) and unintentional (i.e., non-violent). Violence-related fatalities include subway suicides and homicides.

\subsection{Intentional Subway Fatalities}

\subsubsection{Homicides}

Although being pushed onto subway tracks is an extremely rare event, it is a common fear among riders. A survey conducted in 1992 found that $77 \%$ of randomly selected NYC passengers were afraid of being pushed onto the tracks and $80 \%$ took specific protective actions to avoid this (Martell \& Morrison, 1992). The unpredictability and randomness of this type of violence makes it especially frightening. In a study involving violent offenders who pushed or attempted to push people onto NYC subway lines, Martell and Dietz (1992) found that all of the 52 victims of pushing incidents were strangers to the perpetrators. Most of the perpetrators of this type of subway crime are mentally ill, homeless, and have long histories of psychiatric hospitalizations and prior arrests (Martell \& Dietz, 1992). Other types of violent subway crimes, such as stabbings, shootings, and rapes, may also lead to fatalities (Richardson, 1992).

\subsubsection{Subway Suicides}

The other type of violent death that is uniquely associated with subways is attempted or completed suicide by throwing oneself onto the electrified track and/or into the path of an on-coming train. Surprisingly, attempted subway-related suicide is not uniformly lethal. A study of case fatality rates across 23 international subway systems found that subway suicide is lethal approximately $40 \%$ of the time (O'Donnell \& Farmer, 1992). In a review of Montreal coroner's office data from 1986-1996, less than 30\% of the 323 subway suicide attempts were fatal (Mishara, 1999).

\subsection{Unintentional Subway Fatalities}

Unintentional deaths among passengers may result from accidents. Among passengers, non-violent accidental deaths usually result from passengers jumping onto tracks to retrieve personal effects (e.g., purses, cell phones), missteps, sudden illness (e.g., fainting spells), or lack of supervision of children and youth. Thrill seeking teenagers riding on the top or outside of train cars sometimes fall off, resulting in fatal injuries (Mass Transit Association \& New York City Transit). While incursions onto the tracks, as for example, in attempting to retrieve dropped items, is not uniformly fatal, survivors are often seriously wounded (Maclean, O'Neill, Pachter, \& Miglietta, 2006). Sometimes, when these apparently unintentional acts do result in fatality, it appears to be related to the difficulty that individuals have climbing back onto the platform from the tracks (roughly a 4-5 foot height; Beller, 2006; Independent Online, 2004; Lee, 2007). Deaths may also result when passengers are dragged across the platform when their briefcases, handbags, or backpacks are caught in the train doors as the train pulls out of the station (Mass Transit Association \& New York City Transit; Perez-Pena, 1995). In the rare occurrences of train derailment, or other train accident, fatal injuries among passengers can result (Thornton, 2008). The recent Los Angeles head-on collision involving a commuter train and a freight train resulted in 26 fatalities (Sanders, 2008).

\subsection{Undetermined Fatalities}

To reduce the risk of both intentional and unintentional injuries, one on-going problem in determining risk reduction strategies has been to distinguish subway-related suicides from accidental deaths in the absence of witnesses, suicide notes, or history of prior attempts. Many undeter- mined deaths may actually have resulted from suicide. From 1993 to 1996, $39 \%$ of railway "trespassing" fatalities in Canada, including those in aboveground trains, were classified as being the result of "apparent suicide," $10 \%$ were accidents, and the remaining $51 \%$ were classified as "undetermined" (Transport Canada, 1996). In Montreal, one-third of subway fatalities were classified "undetermined" and further investigation revealed that there was a history of suicidal behaviors among the cases, which led researchers to believe that the cases were misclassified (Mishara, 1999).

To characterize subway fatalities in NYC, and to differentiate intentional subway-related fatalities from unintentional subway-related fatalities, we reviewed and analyzed medical examiners' records on all subway-related deaths in NYC between 1990 and 2003.

\section{Methods}

All cases of subway-related fatalities in NYC from 1990 through 2003 were identified through manual review of medical files at the Office of the Chief Medical Examiner of NYC (OCME). The OCME is responsible for assessing all deaths of persons believed to have died in an unnatural manner. Thus, all homicidal, suicidal, and accidental deaths in NYC are reviewed by the OCME and would be included in this chart abstraction. Data regarding demographics, cause of death, race/ethnicity, and circumstances of death were collected. The OCME uses the circumstances of the fatality, autopsy findings, and laboratory data to attribute cause of death to each case reviewed.

Demographic characteristics, toxicological evidence of drugs (including alcohol), NYC borough (Bronx, Queens, Manhattan, Brooklyn, Staten Island), and other circumstances of death for all subwayrelated fatalities, including homicidal, suicidal, and accidental deaths, were determined. To assess differences in decedent characteristics (gender, age, race, NYC borough) and toxicology variables (cocaine, opiates, alcohol, cannabis, as well as a general drug variable including all of the aforementioned as well as benzoylecgonine and ethylbenzoylecgonine, which are metabolites of cocaine) between suicidal and accidental subway-related fatalities, two-tailed chi-square tests were performed. Although both homicidal and suicidal fatalities are violent acts, they are qualitatively different and were not combined for analyses. Furthermore, the sample size of homicidal fatalities was too small for statistical analysis and was thus excluded from the comparison with the other fatality categories. Analyses were performed using SAS, version 9.1 (SAS Institutes, 2002).

This study was reviewed and approved by the Institutional Review Boards at the New York Academy of Medicine and the NYC Department of Health and Mental Hygiene.

\section{Results}

There were a total of 41,388 OCME records for homicides $(n=16,671)$, suicides $(n=7,395)$, and accidental deaths $(n=17,322)$ for the period 1990-2003. Of these fatalities, $668(9.0 \%)$ were subwayrelated, including $10(1.5 \%)$ homicides, $343(51.4 \%)$ suicides, and 315 (47.2\%) accidental deaths. The demographic characteristics of all subway fatalities are presented in Table 1.

\subsection{Subway-Related Intentional Fatalities- Homicides}

Compared to subway-related suicides and accidental deaths, there were far fewer fatalities attributed to homicides $(n=10,1.5 \%)$. Six of the homicide victims were males and four were females. Three of the victims were younger than 24 years old, two victims between 25 years and 34 years, and two victims were between 55 and 64 years old. There was one victim in each of the following age groups: 35 to 44 years old, 45 to 54 years old, and 65 to 74 years old. Six of the subway-related homicide victims were African American. Five of the subway-related homicides took place in Manhattan, three were in the Bronx, and the remaining two occurred in Brooklyn. Toxicology reports 
Table 1

Subway-related fatalities by gender, age, race, borough of injury, and drugs detected, 1990-2003 ( $\mathrm{N}=668)$

\begin{tabular}{|c|c|c|c|c|}
\hline & Suicide $\mathrm{n}(\%)$ & Accident n(\%) & Homicide n(\%) & Total n(\%) \\
\hline \multicolumn{5}{|l|}{ Gender } \\
\hline Male & $269(78.4 \%)$ & $286(90.8 \%)$ & $6(60.0 \%)$ & $561(84.0 \%)$ \\
\hline Female & 74 (21.6\%) & 29 (9.2\%) & $4(40.0 \%)$ & 107 (16.0\%) \\
\hline \multicolumn{5}{|l|}{ Age } \\
\hline $0-24$ & $42(12.2 \%)$ & $44(14.0 \%)$ & $3(30.0 \%)$ & $89(13.3 \%)$ \\
\hline $25-34$ & $96(28.0 \%)$ & $71(22.5 \%)$ & $2(20.0 \%)$ & $169(25.3 \%)$ \\
\hline $35-44$ & $88(25.7 \%)$ & $88(27.9 \%)$ & $1(10.0 \%)$ & $177(26.5 \%)$ \\
\hline $45-54$ & $56(16.3 \%)$ & $55(17.5 \%)$ & $1(10.0 \%)$ & $112(16.8 \%)$ \\
\hline $55-64$ & $24(7.0 \%)$ & $40(12.7 \%)$ & $2(20.0 \%)$ & $66(9.9 \%)$ \\
\hline $65-74$ & $18(5.3 \%)$ & $10(3.2 \%)$ & $1(10.0 \%)$ & $29(4.3 \%)$ \\
\hline $75+$ & $19(5.5 \%)$ & $7(2.2 \%)$ & 0 & $26(3.9 \%)$ \\
\hline \multicolumn{5}{|l|}{ Race } \\
\hline White & 130 (37.9\%) & 91 (28.9\%) & $1(10.0 \%)$ & $222(33.2 \%)$ \\
\hline Non-White & $213(62.1 \%)$ & $224(71.1 \%)$ & $9(90.0 \%)$ & $446(66.8 \%)$ \\
\hline \multicolumn{5}{|c|}{ Borough of injury } \\
\hline Manhattan & $137(40.3 \%)$ & $146(47.3 \%)$ & $5(50.0 \%)$ & $288(43.1 \%)$ \\
\hline Bronx & 37 (10.9\%) & $39(12.6 \%)$ & $3(30.0 \%)$ & $79(11.8 \%)$ \\
\hline Brooklyn & 95 (28.0\%) & $88(28.5 \%)$ & $2(20.0 \%)$ & $185(27.7 \%)$ \\
\hline Queens & $70(20.6 \%)$ & $34(11.0 \%)$ & 0 & $104(15.6 \%)$ \\
\hline Staten Island & $1(0.3 \%)$ & $2(0.7 \%)$ & 0 & $3(0.4 \%)$ \\
\hline \multicolumn{5}{|c|}{ Toxicological evidence of any drug* (including alcohol) } \\
\hline Yes & $108(31.5 \%)$ & $198(62.9 \%)$ & $4(40.0 \%)$ & $310(46.4 \%)$ \\
\hline No & $235(68.5 \%)$ & $117(37.1 \%)$ & $6(60.0 \%)$ & $358(53.6 \%)$ \\
\hline \multicolumn{5}{|l|}{ Cocaine } \\
\hline Yes & $43(12.5 \%)$ & $69(21.9 \%)$ & $2(20.0 \%)$ & $114(17.1 \%)$ \\
\hline No & $300(87.5 \%)$ & $246(78.1 \%)$ & $8(80.0 \%)$ & $554(82.9 \%)$ \\
\hline \multicolumn{5}{|l|}{ Opiates } \\
\hline Yes & $23(6.7 \%)$ & $26(8.3 \%)$ & 0 & $49(7.3 \%)$ \\
\hline No & $320(93.3 \%)$ & $289(91.8 \%)$ & $10(100.0 \%)$ & $616(92.2 \%)$ \\
\hline \multicolumn{5}{|l|}{ Alcohol } \\
\hline Yes & $61(17.8 \%)$ & $145(46.0 \%)$ & 0 & $206(30.8 \%)$ \\
\hline No & $282(82.2 \%)$ & $170(54.0 \%)$ & $10(100.0 \%)$ & $462(69.2 \%)$ \\
\hline \multicolumn{5}{|l|}{ Cannabis } \\
\hline Yes & $21(6.1 \%)$ & $21(6.7 \%)$ & $3(30.0 \%)$ & $45(6.7 \%)$ \\
\hline No & $322(93.9 \%)$ & $294(93.3 \%)$ & $7(70.0 \%)$ & $623(93.3 \%)$ \\
\hline \multicolumn{5}{|c|}{ Any drug* (not including alcohol) } \\
\hline Yes & $73(21.3 \%)$ & $98(31.1 \%)$ & $4(40.0 \%)$ & $171(25.6 \%)$ \\
\hline No & $270(78.7 \%)$ & $217(68.9 \%)$ & $6(60.0 \%)$ & 487 (72.9\%) \\
\hline
\end{tabular}

$* \operatorname{Drug}(\mathrm{s})$ include toxicological presence of any of the following drugs: cocaine, opiates, pcp, benzoylecgonine, ethylebenzoylecgonine, cannabinoids, and alcohol unless indicated otherwise.

indicated that two victims tested positive for cocaine and three victims tested positive for cannabis.

\subsection{Subway-Related Intentional Fatalities- Suicides}

Among subway-related suicide fatalities, a greater proportion of men ( $n=269,78.4 \%$ ) than women $(n=74,21.6 \%)$ committed suicide by subway, and the largest percentage were between the ages of $25-34$ years $(n=96$, $28.0 \%$ ), as shown in Table 1 . A greater proportion of suicides were nonWhite (Black, Hispanic, Asian/Other combined; $n=213,62.1 \%$ ) compared to White ( $n=130,37.9 \%$ ). More subway-related suicides occurred in Manhattan ( $n=137,40.3 \%)$ than any other borough. One or more illicit drugs (not including alcohol) was detected in $21.3 \%(n=73)$ of subwayrelated suicides and alcohol was present in $17.8 \%(n=61)$. A positive toxicology report for both illicit drugs and alcohol was detected in $31.5 \%$ $(n=108)$.

\subsection{Subway-Related Unintentional Fatalities- Accidents}

A much greater proportion of victims of accidental fatalities were men $(n=286,90.8 \%)$ than women $(n=29,9.2 \%)$. The largest percentage were between the ages of $35-44(n=88,27.9 \%)$ and $25-34$ years $(n=71,22.5 \%)$. Accidental deaths were more likely to be among non-Whites (Black, Hispanic, Asian/Other combined; $\mathrm{n}=224,71.1 \%$ ) compared to Whites $(n=91,28.9 \%)$. And, similar to subway-related suicide fatalities, the majority of subway-related accidental deaths occurred in Manhattan
( $n=146,47.3 \%$ ). One or more illicit drugs (not including alcohol) was detected in $31.1 \%$ ( $n=98)$ of accidental fatalities, and alcohol was detected in $46.0 \%(n=145)$. Evidence of both illicit drugs and alcohol was noted in $62.9 \%(n=198)$ of the victims. When men and women were compared, men were significantly more likely to have positive toxicological screens, including alcohol, than women $(p<.01)$.

\subsection{Comparison of Intentional (suicides and homicides) Subway-Related Fatalities}

As previously mentioned, there was an insufficient sample size of subway-related homicides to allow for statistical analysis and comparison between these two forms of intentional fatalities.

\subsection{Comparison of Unintentional to Intentional (suicides) Subway- Related Fatalities}

Demographic and toxicological decedent characteristics of subway-related suicide and accident victims were compared, as shown in Table 2. Significant differences were noted between the two fatality categories. Specifically, subway-related suicides were significantly $(p<.05)$ more likely to be women, between the ages of 25-34, White, have occurred in Queens, and less likely to have positive toxicology screens for illicit drugs (such as cocaine) or alcohol than unintentional subway-related fatalities. We examined gender differences with

Table 2

Comparison of subway-related suicide and accidental fatalities

\begin{tabular}{|c|c|c|c|}
\hline & $\begin{array}{l}\text { Suicide } \\
\mathrm{n}(\%)\end{array}$ & $\begin{array}{l}\text { Accident } \\
\mathrm{n}(\%)\end{array}$ & $\begin{array}{l}\mathrm{X}_{2} \\
\mathrm{p} \text {-value }\end{array}$ \\
\hline Gender & & & $<.001$ \\
\hline Male & $269(78.4 \%)$ & $286(90.8 \%)$ & \\
\hline Female & $74(21.6 \%)$ & $29(9.2 \%)$ & \\
\hline Age & & & 0.03 \\
\hline $0-24$ & $42(12.2 \%)$ & $44(14.0 \%)$ & \\
\hline $25-34$ & $96(28.0 \%)$ & $71(22.5 \%)$ & \\
\hline $35-44$ & $88(25.7 \%)$ & $88(27.9 \%)$ & \\
\hline $45-54$ & $56(16.3 \%)$ & $55(17.5 \%)$ & \\
\hline $55-64$ & $24(7.0 \%)$ & $40(12.7 \%)$ & \\
\hline $65-74$ & $18(5.3 \%)$ & $10(3.2 \%)$ & \\
\hline $75+$ & $19(5.5 \%)$ & $7(2.2 \%)$ & \\
\hline Race & & & 0.01 \\
\hline White & $130(37.9 \%)$ & $91(28.9 \%)$ & \\
\hline Non-White & $213(62.1 \%)$ & $224(71.1 \%)$ & \\
\hline Borough of injury & & & 0.02 \\
\hline Manhattan & $137(40.3 \%)$ & $146(47.3 \%)$ & \\
\hline Bronx & $37(10.9 \%)$ & $39(12.6 \%)$ & \\
\hline Brooklyn & $95(28.0 \%)$ & $88(28.5 \%)$ & \\
\hline Queens & $70(20.6 \%)$ & $34(11.0 \%)$ & \\
\hline Staten Island & $1(0.3 \%)$ & $2(0.7 \%)$ & \\
\hline $\begin{array}{l}\text { Toxicological evidence of any drug* } \\
\text { (including alcohol) }\end{array}$ & & & $<0.001$ \\
\hline Yes & $108(31.5 \%)$ & $198(62.9 \%)$ & \\
\hline No & $235(68.5 \%)$ & $117(37.1 \%)$ & \\
\hline Cocaine & & & $<0.01$ \\
\hline Yes & $43(12.5 \%)$ & 69 (21.9\%) & \\
\hline No & $300(87.5 \%)$ & $246(78.1 \%)$ & \\
\hline Opiates & & & 0.45 \\
\hline Yes & $23(6.7 \%)$ & $26(8.3 \%)$ & \\
\hline No & $320(93.3 \%)$ & $289(91.8 \%)$ & \\
\hline Alcohol & & & $<0.001$ \\
\hline Yes & $61(17.8 \%)$ & $145(46.0 \%)$ & \\
\hline No & $282(82.2 \%)$ & $170(54.0 \%)$ & \\
\hline Cannabis & & & 0.78 \\
\hline Yes & $21(6.1 \%)$ & $21(6.7 \%)$ & \\
\hline No & 322 (93.9\%) & 294 (93.3\%) & \\
\hline Any drug* (not including alcohol) & & & $<0.01$ \\
\hline Yes & $73(21.3 \%)$ & $98(31.1 \%)$ & \\
\hline No & $270(78.7 \%)$ & $217(68.9 \%)$ & \\
\hline
\end{tabular}

* Drug(s) include toxicological presence of any of the following drugs: cocaine, opiates, $\mathrm{pcp}$, benzoylecgonine, ethylebenzoylecgonine, cannabinoids, and alcohol unless indicated otherwise. 
respect to toxicological results and found that within the suicide group, men were significantly more likely to have a positive test for alcohol compared to women $(p<.01)$ (data not shown).

\section{Discussion}

The demographic characteristics of subway fatalities in the NYC transit system are similar to those found in other subway studies, at least for the limited number of variables available. For example, studies have shown that the majority of subway suicides are generally between the ages of 2030 years, and in our study a similar distribution was found. Regarding gender, studies have consistently shown that men are more likely to commit subway-related suicide compared to women, with ratios ranging from 1.58:1 to 2.5:1 (Ratnayake et al., 2007). Although the male/female ratio was higher (3.6:1) in our study, the ratio we found is similar to the male/female ratio in the United States for all suicides (4.45:1, all ages; Centers for Disease Control and Prevention, 2007). Lack of other variables in common (e.g., race) and other methodological issues make demographic and other comparisons across subway studies difficult.

With respect to substance use associated with subway-related suicide, data, while sparse, indicate that a sizeable proportion of suicides have positive toxicological screens (Ratnayake et al., 2007), and in our study we noted similar findings, with evidence for alcohol (18\%) and illicit drugs (21\%) among suicides.

In terms of subway-related unintentional fatalities, in our study, the male/female ratio was very high $(10: 1)$ compared to U.S. unintentional fatalities, (4.5:1, all ages) (National safety Council, 2006). In examining this further, we found that male accident victims were much more likely to have positive alcohol screens than women accident victims $(p<.01)$. These data suggest that alcohol may contribute to unintentional subway-related fatalities, perhaps in association with thrill-seeking behaviors, such as "surfing" the top of train cars.

Although a substantial proportion of women were victims of homicide (40.0\%), when we compare the gender ratios of the victims of subway homicide (1.5:1) to the U.S. homicide ratio (3.84:1, all ages), subway ratios are lower (Centers for Disease Control and Prevention, 2007). However, the small number of subway homicides in our sample and the lack of comparable data from other subway studies limit our ability to draw inferences on these subway homicides.

Within our sample, when we compare the subway accident fatalities to the subway suicide group, we note several significant differences. For example, while a higher proportion of fatalities occurred overall in Manhattan, which has the largest ridership population and the greatest number of subway stops and platforms, suicides were more likely to occur in the borough of Queens. We cannot discern the reason for this from the available data. We also found that nearly $63 \%$ of all accident victims had positive toxicology reports for illicit drugs and alcohol compared to only $32 \%$ for suicides $(p<.001)$. These fatal accidents may have resulted from intoxication, as noted above, but causality cannot be ascertained from these data. However these data are similar to automobile fatality statistics in that approximately $40 \%$ of persons killed in fatal car accidents have positive blood alcohol tests (Fatality Analysis Reporting System Encyclopedia) and roughly 10\% of automobile fatalities involve illicit drugs (Armentano, 2008). Similarly, a 10-year review of fatal falls noted that in $54 \%$ of the incidents, the victim had high blood alcohol concentrations (Bux, Parzeller, \& Bratzke, 2007). This is of interest here because in some urban settings driving is uncommon (more than $75 \%$ of Manhattan households do not own a car; Bureau of Transportation Statistics, 2001), and it might therefore seem that intoxication is not risky. However these data suggest that intoxication combined with subway ridership may be associated with accidental death. This is a public health message that has not, to our knowledge, been communicated to the general public. In particular, men appear to be at increased risk of fatal subway-related accidents due to intoxication.
Implementation of individual-level interventions will probably not be particularly helpful in reducing unintentional and intentional (suicidal) fatalities. Public awareness and both public safety and public health educational campaigns targeting unsafe behaviors on platforms and in and around subway cars may have some benefit for reducing unintentional fatalities. However, as noted in a similar study on railroad-related deaths in Sweden, the nature of subway suicide attempts, which appear to be without warning, make them difficult to prevent (Rådbo et al., 2005), although limiting media coverage of these events has shown to minimize their occurrence (Etzersdorfer \& Sonneck, 1998). More general strategies designed to improve safety overall may also help reduce the risk of all forms of subway-related fatalities.

\subsection{Strategies for Improving Subway Safety}

\subsubsection{Engineering Strategies}

In the field of safety, the most effective method of reducing the risk of injury and fatality in dangerous environments is through the application of structural design elements and barriers that essentially serve to "engineer out" risk (Haddon, 1980). In the subway environment, this would include adequate lighting, well-functioning and structurally sound equipment (including elevators and escalators, as well as subway cars and rails), clear egress paths, easy to follow signage, effective communication systems, good housekeeping, and other standard environmental controls that improve safety outcomes. Physical barriers that limit passenger access to tracks, including platform screen doors (PSD) and platform edge doors (PED), which separate the rail from the platform, are known to be extremely effective in preventing incursions onto the track. These types of design elements, in which train doors and platform doors open simultaneously at pre-designated stops, create an effective barrier between the passenger and the track ("Platform Screen Doors"). This type of system would therefore eliminate fatal incursions onto the track. An important limitation to this system, however, is cost; the Hong Kong subway system was recently retrofitted to add these barriers at a cost of HK $\$ 2$ billion (equivalent of $\$ 256$ million USD) and this only involved 74 platforms in 30 underground stations (MTR Corporation Limited, 2007). By contrast, in NYC, there are 468 stations, each with two or more platforms (Metropolitan Transportation Authority, 2006).

Another engineering design approach is the use of drainage pits that are located under railway tracks. These pits increase the distance between the train and the ground, thus allowing an individual who has fallen or jumped onto the tracks to lie safely underneath, albeit inches, away from the train wheels. In the London subway system, these pits, which were initially introduced to improve drainage, resulted in a decrease of all cause fatalities; the mortality rate for persons who fell or jumped onto tracks with drainage pits was $44 \%$ compared to $76 \%(p=0.026)$ of incursions onto tracks without drainage pits (Coats \& Walter, 1999).

\subsubsection{Policing Strategies}

Increasing the visibility of police and lowering the level of disorder on subways is an important component to reducing the overall climate for violent crime, as well as the fear of violent crime. For this reason, many subway systems, including the NYC MTA and the Hong Kong Mass Transit Railway, designed policing systems to mitigate crime (Gaylord \& Galliher, 1991). In addition to various structural components, such as video surveillance on platforms to identify suspicious activity and training for transit workers to identify and restrain individuals, transit police were trained to recognize situations in which a violent act may occur and taught various methods to avoid such situations (Gaylord \& Lester, 1994). Comparisons of data on violent crimes between subway systems and the effectiveness of different approaches to transit policing are difficult to assess due to limited available data. However, in NYC, these policing strategies were associated with significant reductions in subway crime rates (Mass Transit Association \& New York City Transit). 


\subsubsection{Social Approaches}

A reduction of media coverage of subway suicide events has been shown to be effective in reducing the incidence of new cases. In mid1987, the media in Vienna, Austria stopped reporting on subway suicides and the rate dropped more than 80\% from the first to second half of 1987 (Etzersdorfer \& Sonneck, 1998). For this reason, many countries have issued guidelines to reporters regarding media coverage of suicides, including the United States, the United Kingdom, New Zealand, Australia, and Hong Kong (The Hong Kong Jockey Club Centre for Suicide Research and Prevention). The World Health Organization (WHO) identified the media as one of the obstacles to suicide prevention, noting that effective interventions consist of a multi-sectoral approach, including those outside of the health sector (World Health Organization, 2007). With regards to the risk of unintentional fatalities, public information campaigns aimed especially at parents of young children, teenagers, and young adults, would probably have the greatest impact. Public messages, similar to the ones developed to discourage drunk driving, might be similarly effective in raising the awareness of the risk associated with intoxication while riding the subway.

\section{Summary}

Statistical analysis of all subway-related fatalities in NYC from 1990-2003, support the contention that the application of multi-level approaches (i.e., engineering controls, improved policing, and social approaches, including educational campaigns directed to the ridership and reducing media coverage of suicides) to subway safety will be most effective in reducing all causes of subway fatalities among ridership.

\section{References}

American Public Transportation Association. (2001). Total Injuries by Mode, 2001 Retrieved Dec, 2007, from http://www.apta.com/research/stats/safety/safeinjv.cfm American Public Transportation Association. (2005). Fatalities by Mode Retrieved Dec, 2007, from http://www.apta.com/research/stats/safety/safefatv.cfm

American Public Transportation Association. (2005). Passenger Miles by Mode Retrieved Dec, 2007, from http://www.apta.com/research/stats/ridershp/passmile.cfm

American Public Transportation Association. (2006). Fatality Rates by Mode of Travel Retrieved Dec, 2007, from http://www.apta.com/research/stats/safety/natsafe.cfm

Armentano, P. (2008). Cannabis and driving: A scientific and rational review. Washington, DC: The National Organization for the Reform of Marijuana Laws.

Baumert, J., Erazo, N., \& Ladwig, K. H. (2006). Ten-year incidence and time trends of railway suicides in Germany from 1991 to 2000. European Journal of Public Health, $16(2), 173-178$.

Beller, T., (2006, February 12). IPod on the tracks. The New York Times Retrieved Nov, 2008, from http://www.nytimes.com/2006/02/12/nyregion/thecity/12ipod.html

Bureau of Transportation Statistics. (2001). Highlights of the 2001 National Household Travel Survey. Washington, DC: U.S. Department of Transportation.

Bux, R., Parzeller, M., \& Bratzke, H. (2007). Causes and circumstances of fatal falls downstairs. Forensic Science International, 171(2-3), 122-126.

Centers for Disease Control and Prevention. (2007). NCHS-FASTATS- Suicide Retrieved Nov, 2007, from http://www.cdc.gov/nchs/fastats/suicide.htm

Clarke, M. (1994). Railway suicide in England and Wales, 1850-1949. Social Science \& Medicine, 38(3), 401-407.

Coats, T. J., \& Walter, D. P. (1999). Effect of station design on death in the London underground: Observational study. BMJ, 319, 957.

Etzersdorfer, E., \& Sonneck, G. (1998). Preventing suicide by influencing mass-media reporting: The Viennese experience 1980-1996. Archives of Suicide Research, 4, 67-74.

Fatality Analysis Reporting System Encyclopedia. Persons killed, by highest blood alcohol concentration (BAC) in the crashes, 1994-2006-State: USA. Retrieved May 19, 2008, from http://www-fars.nhtsa.dot.gov/trends/trendsalcohol.aspx

Gaylord, M. S., \& Galliher, J. (1991). Riding the underground dragon: crime control and public order on Hong Kong's mass transit railway. British Journal of Criminology, 31, $15-26$.

Gaylord, M. S., \& Lester, D. (1994). Suicide in the Hong Kong subway. Social Science E' Medicine, 38(3), 427-430.

Haddon, W. (1980). Options for the prevention of motor vehicle crash injury. Israel Journal of Medical Sciences, 16, 45-65.

Independent Online. (2004, July 30). Man crushed to death in Munich subway from http:// www.iol.co.za/index.php?set_id=1\&click_id=24\&art_id=qw1091183401796B265

Jane's Urban Transport Systems. (2002-2003 ed.). World's Largest Subway Systems Retrieved Dec, 2007, from http://www.infoplease.com/ipa/a0762446.html

Ladwig, K. H., \& Baumert, J. J. (2004). Patterns of suicidal behaviour in a metro subway system: a study of 306 cases injured by the Munich subway, 1980-1999. European Journal of Public Health, 14(3), 291-295.
Lee, J., (2007, August 24). Bronx: Man is fatally struck by train. The New York Times Retrieved Nov, 2008, from http://www.nytimes.com/2007/08/24/nyregion/ 24mbrfs-subway.html

Maclean, A. A., O'Neill, A., Pachter, L., \& Miglietta, M. (2006). Devastating consequences of subway accidents: Traumatic amputations. The American Surgeon, 72, 74-76.

Martell, D., \& Dietz, P. (1992). Mentally disordered offenders who push or attempt to push victims onto subway tracks in New York City. Archives of General Psychiatry, 49, 472-475.

Martell, D., \& Morrison, D. (1992). Public perceptions of the mentally ill and danger in the subways: A representation survey of Manhattan subway riders. Field Study Technical Paper (pp. 92-101). Orangeburg, NY: Nathan S. Kline Institute for Psychiatric Research, New York State Office of Mental Health.

Mass Transit Association, \& New York City Transit. If You See Something, Say Something. Retrieved Feb, 2008, from http://mta.info/mta/security/index.html

Mass Transit Association, \& New York City Transit. MTA NYC Transit- Riding Safely. Retrieved Feb, 2008, from http://mta.info/nyct/safety/

Metropolitan Transportation Authority. The MTA Network. Retrieved Dec 17, 2007, from http://www.mta.info/mta/network.htm

Metropolitan Transportation Authority. (2006). MTA NYC Transit Info Retrieved April, 2008, from http://www.mta.info/nyct/facts/ffsubway.htm

Mishara, B. L. (1999). Suicide in the Montreal subway system: Characteristics of the victims, antecedents, and implications for prevention. Canadian Journal of Psychiatry, 44(7), 690-696.

Mishara, B. L. (2007). Railway and metro suicides: Understanding the problem and prevention potential. Crisis, 28(1), 36-43.

MTR Corporation Limited. (2007), MTR Corporation Limited-Sustainability Report Retrieved Feb, 2008, from http://www.mtr.com.hk/eng/sustainability/sustainrpt/ 2006rpt/sia-2005-psd.html

National Safety Council. (2006), Injury Facts. 2005-2006 ed. Itasca, IL: Author.

Nelson, A., Dawkins, C., \& Sanchez, T. (2007). The Social Impacts of Urban Containment. Great Britain: Ashgate Publishing Company.

O'Donnell, I., Arthur, A. J., \& Farmer, R. D. (1994). A follow-up study of attempted railway suicides. Social Science E Medicine, 38(3), 437-442.

O'Donnell, I., \& Farmer, R. D. (1992). Suicidal acts on metro systems: An international perspective. Acta Psychiatrica Scandinavica, 86, 60-63.

O'Donnell, I., \& Farmer, R. D. (1994). The epidemiology of suicide on the London Underground. Social Science E' Medicine, 38(3), 409-418.

Perez-Pena, R. (1995, April 13). Preventives for '87 subway death still not in use.The New York Times Retrieved Nov, 2008, from http://query.nytimes.com/gst/fullpage.html? res=990CE7D9153FF930A25757C0A963958260

Platform Screen Doors. Retrieved Nov, 2007, from http://www.mic-ro.com/metro/ platform-screen-doors.html

Rådbo, H., Svedung, I., \& Andersson, R. (2005). Suicides and other fatalities from trainperson collisons on Swedish railroads: A descriptive epidemiologic analysis as a basis for system-oriented prevention. Journal of Safety Research, 36, 423-428.

Ratnayake, R., Links, P. S., \& Eynan, R. (2007). Suicidal behaviour on subway systems: A review of the epidemiology. Journal of Urban Health, 85(1), 149.

Richardson, L. (1992, January 26). Queens man robbed and killed aboard subway.The New York Times Retrieved Nov, 2008, from http://query.nytimes.com/gst/fullpage. html?res=9E0CE1DE1138F935A15752C0A964958260

Sanders, P. (2008, September 15). Spokeswoman for Metrolink Resigns in Wake of Comments Over AccidentThe Wall Street Journal. (pp. ) from http://online.wsj.com/article/ SB122149839155137081.html? $\bmod =$ special_page _ campaign2008 mostpop

SAS Institutes. (2002). SAS (Version 9.1). Cary, NC: Author.

The Hong Kong Jockey Club Centre for Suicide Research and Prevention. Suicide and the Media: Recommendations on Suicide Reporting for Media Professionals. Hong Kong: The University of Hong Kong Retrieved Nov, 2008, from http://csrp.hku.hk/ files/70_1894_345.pdf

The Light Rail Transit Association. (2006). A World of Trams and Urban Transit Retrieved Dec, 2007, from http://www.lrta.org/world/worldind.html

Thornton, A. (2008). How safe is the New York City subway? Retrieved April 11, 2008, from http://www.nysubway.com/safety.subwaysafety.html

Transport Canada. (1996). Right Track Rail Safety Retrieved Feb, 2008, from http://www. sickkids.ca/SKCForParents/custom/RailSafety.pdf

United Nations Population Fund. (2007). State of world population: Unleashing the potential of urban growth Retrieved Feb, 2008, from http://www.unfpa.org/swp/ 2007/presskit/pdf/sowp2007_eng.pdf

World Health Organization. (2007). Suicide Prevention (SUPRE) Retrieved Nov, 2007, from http://www.who.int/mental_health/prevention/suicide/suicideprevent/en/

Robyn R.M. Gershon, MHS, DrPH, received her doctorate in public health from the Johns Hopkins Bloomberg School of Public Health. She is an occupational health and safety researcher with nearly 20 years of experience in conducting complex large scale occupational health research studies, with a focus on high-risk work populations. She is a Professor of Clinical Sociomedical Sciences at the Mailman School of Public Health at Columbia University in New York City with a joint appointment in the School of Nursing.

Julie M. Pearson, BA, is currently a graduate student in the Department of Sociomedical Sciences at the Mailman School of Public Health at Columbia University in New York City. She received her Bachelor of Arts degree in psychology from Loyola College in Maryland. Ms. Pearson has extensive public health experience. She was a health educator for at-risk children and adolescents as a Community HealthCorps volunteer, a national AmeriCorps program. Ms. Pearson is interested in studying determinants of health behavior. 
Vijay Nandi, MPH, received her Master's in Public Health in epidemiology from New York Medical College and her Bachelor of Arts degree in political science from Middlebury College. She is a Senior Research Analyst in the Center for Urban Epidemiologic Studies at The New York Academy of Medicine. She is currently working on studies that explore a range of social and health issues in the Mexican immigran population and urban population as well as evaluating programs in the areas of cardiovascular health and social work education as it relates to aging.

David Vlahov, PhD, is the director for the Center for Urban Epidemiologic Studies at the New York Academy of Medicine, Professor of Clinical Epidemiology at the Mailman School of Public Health, and adjunct professor in Epidemiology at the Johns Hopkins Bloomberg School of Public Health where he received his doctorate. He brings expertise in epidemiology, infectious diseases, substance abuse, and mental health. Dr. Vlahov has conducted studies of urban populations in Baltimore for over 20 years including several longitudinal cohort studies for which he received the NIH MERIT Award. More recently, Dr. Vlahov led epidemiologic studies in Harlem and the Bronx, which have served as a platform for subsequent individual- and community-level intervention studies and community-based participatory research (involving partnerships with residents, community-based organizations, academic/ public health departments) to address social determinants of health.

Angela Bucciarelli-Prann, MPH, received her Master's in Public Health from Drexe University. Her past research interest include urban public health issues especially mortality trends within New York City and mental health sequaelae following the events surrounding the September 11th terrorist attack. More recently, the use of spatio-temporal analyses in disease surveillance have been of particular research interest. Mrs. Bucciarelli-Prann has work in the past with the New York Academy of Medicine - Center for Urban Epidemiologic Studies and New York City Department of Health and Mental Hygiene - World Trade Center Health Registry. Currently, she work within the biostatistical research core at Hackensack University Medical Center in Hackensack, New Jersey.

Melissa Tracy, MPH, is a doctoral student in the Department of Epidemiology at the University of Michigan School of Public Health. She received her Master's in Public Health in Epidemiology from the University of Washington School of Public Health and Community Medicine. Her research interests include understanding the macro-social determinants of population health, applying complex systems modeling and spatia analysis to population health, and the epidemiology of depression, posttraumatic stress disorder, and substance use.

Kenneth Tardiff, MD, MPH, received his doctorate from Tulane University School of Medicine. He completed a psychiatric residency at the Massachusetts General Hospital and received his Master's in Public Health from the Harvard School of Public Health. Dr. Tardiff has been on the faculty at the University of British Columbia and State University of New York at Stony Brook. Currently, he is a Professor of Psychiatry and Public Health at Weill Medical College of Cornell University. Dr. Tardiff has published roughly 200 journal articles, books and chapters mostly on violence, suicide and drug abuse. He has also served as an expert witness in these areas.

Sandro Galea, MD, DrPH, MPH, is a Professor of Epidemiology at the School of Public Health and a Research Professor at the Institute of Social Research, both at the University of Michigan. Dr Galea did his graduate training at the University of Toronto Medical School, at the Harvard University School of Public Health, and at the Columbia University Mailman School of Public Health. Dr Galea is primarily interested in the social and economic production of health, particularly mental health and behavior in urban settings. He has an abiding interest in the health consequences of collectively experienced traumatic events. 